\title{
FONTES DO DIREITO COMO EXPRESSÕES \\ LINGUÍSTICAS DE NORMAS JURÍDICAS E SUA \\ HIERARQUIA: UMA VISÃO RETÓRICA
}

\author{
SOURCES OF LAW AS LINGUISTIC EXPRESSIONS OF LEGAL NORMS AND THEIR \\ HIERARCHY: A RHETORICAL VIEW
}

\section{FUENTES DEL DERECHO COMO EXPRESIONES LINGUÍSTICAS DE NORMAS JURIDICAS Y SU JERARQUIIA: UNA VISIÓN RETÓRICA}

Licença CC BY:

Artigo distribuído sob os termos Creative Commons, permite uso e distribuição irrestrita em qualquer meio desde que $o$ autor credite a fonte original.

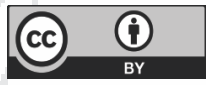

\section{João Maurício Adeodato ${ }^{1}$}

Palavras-chave: Fontes do direito como linguagem - Metodologia retórica indutiva (epagogé) - História das ideias - Hierarquia das fontes do direito - Conceito de sujeito.

Abstract: This paper aims to show that the so-called sources of law consist of linguistic signifiers, with the function of initiating the process of conflict resolution, the object of legal praxis, and knowledge, the object of philosophy, jurisprudence and legal dogmatic. The methodology of inductive rhetoric (epagogé) is used, within the history of ideas, and also concept analysis, which avoids any form of ontology. After outlining the debate on the theory of the sources of law, highlighting the controversies relating to their hierarchy, the text shows that it provided one of the important landmarks for the emergence of two related and very important ideas: the origin of law and the notion of the individual. This historical view of pragmatic rhetoric concludes that the concept of subject represents a reaction of the individuals to the constraints imposed by positive law, a system that resists their individualities.

1 Mestre, Doutor e Livre-Docente pela Faculdade de Direito da Universidade de São Paulo, Ex-Professor Titular da Faculdade de Direito do Recife, Pesquisador 1-A do CNPq, Professor Convidado e Pesquisador da Alexander von Humboldt-Stiftung. Professor Titular de Filosofia do Direito e Retórica Jurídica da Faculdade de Direito de Vitória, Espírito Santo, Brasil. jmadeodato@gmail.com. 
Keywords: Sources of law as language - Inductive rhetorical methodology (epagogé) - History of ideas Hierarchy of the sources of law - Concept of subject.

Resumen: Este trabajo tiene por objetivo mostrar que las llamadas fuentes del derecho constituyen significantes, con función de dar inicio al proceso de decisión de conflictos, para el cual se dirige la dogmática práctica, y de conocimiento, para el cual se dirigen la filosofía, la teoría general y la dogmática jurídica. La metodología es la retórica inductiva (epagogé), dentro de la historia de las ideas y del análisis de los conceptos, y se aleja de cualquier ontología. Trás exponer el debate de la teoría de las fuentes, resaltando las controversias sobre su jerarquía, el texto muestra que ella proporcionó uno de los marcos importantes para el surgimiento de dos ideas conexas y de gran importancia: el origen del derecho y la noción de individuo. Esta visión histórica de la retórica pragmática concluyó que el concepto de sujeto representa una reacción del individuo delante de los constreñimientos impuestos por el derecho positivo, una orden que resiste a sus individualidades.

Palabras clave: Fuentes del derecho como lenguaje - Metodología retórica inductiva (epagogé) Historia de las ideas - Jerarquía de las fuentes del derecho - Concepto de sujeto.

\section{INTRODUÇÃO}

Segundo os romanistas, o conceito de fonte (do latim fons - fontis), no plano jurídico, foi criado por Cícero ou, pelo menos, difundido por ele. Apesar de datada do século I a.C., contudo, a metáfora só passou a ter utilização generalizada por volta do século VI d.C., com uma diferença de sete séculos entre sua criação e sua inserção no vocabulário dos juristas. ${ }^{2}$ Muitos, desde então, têm sugerido expressões para substituí-la, tais como "modelos jurídicos", "fatos de produção normativa" ou simplesmente "fatos normativos"; porém, por diversos motivos, nenhuma delas caiu no uso corrente. ${ }^{3}$

Nesta temática, o artigo objetiva mostrar que as chamadas fontes do direito constituem significantes, com função de dar início ao processo de decisão de conflitos, para o qual se dirige a dogmática prática, e de conhecimento, para o qual se dirigem a filosofia, a teoria geral e a dogmática jurídica. A metodologia é a retórica indutiva (epagogé), dentro da história das ideias e da análise dos conceitos, e afasta-se de qualquer ontologia. Após expor o debate em torno da teoria das fontes, ressaltando as controvérsias sobre sua hierarquia, o texto conclui que ela forneceu um dos marcos importantes para o surgimento de duas ideias conexas e de grande importância: a origem do direito e a noção de indivíduo.

A metáfora foi inspirada no local onde a água aparece ou de onde brota, mas também na origem inicial, como a nascente ou o lençol freático de onde a água provém. Esse significado ambíguo impregna até hoje o uso da expressão. Por isso mesmo, os diversos autores oferecem as mais 
variadas classificações, tais como fontes diretas, indiretas, imediatas, mediatas, primárias, secundárias, históricas, etc. Neste texto, vai-se utilizar um método retórico e pragmático de abordagem para tentar demonstrar que esses usos podem ser simplificados e mais claramente definidos, à luz da evolução histórica do conceito, o qual é vago, ambíguo e tem variado muito ao longo da história das ideias da cultura jurídica ocidental.

Aqui, as fontes do direito são tratadas como linguagem, significantes dirigidos ao direito. Segundo essa sugestão da filosofia retórica, no início da gnose do mundo empírico, aparece um evento, que a linguagem comum denomina "fato", o qual é único e nunca se repete, como percebeu Heráclito ao comparar o mundo real com o fluxo de um rio. Para perceber esse evento, o ser humano lança mão da linguagem, signos com os quais procura compreendê-lo e que formam o segundo elemento do processo. A esses signos, porém, são atribuídos diferentes significados, pois eles não têm um sentido (ambiguidade) nem um alcance (vagueza) precisos, e este constitui o terceiro e último elemento do conhecimento.

No campo do direito, um conjunto de eventos relevantes, que os juristas denominam "fato jurídico", precisa ter seu significado específico determinado diante de certos "significantes", como a lei e a jurisprudência, dentre outros. As pessoas envolvidas no discurso argumentam, então, que "significado" atribuem àqueles textos alegados diante dos fatos em questão. A norma jurídica será o relato que o direito positivo fixar no final do processo, determinando o que a lei, por exemplo, significa diante do caso concreto.

Para colocar um exemplo, imagine-se um acidente de automóvel com uma vítima fatal, um evento que, como qualquer outro, jamais acontecerá da mesma maneira. O ordenamento jurídico traz textos com conceitos destinados a apreender aquele fato jurídico, tais como "culpa da vítima", "culpa do agente", "dolo eventual" e "dolo premeditado", dentre outros. Os participantes do debate vão argumentar com o objetivo de nomear aquele evento segundo um ou outro texto: o advogado de defesa pode dizer que foi culpa da vítima; a delegada de polícia, que foi crime culposo; o promotor, que foi dolo premeditado; ao final, o sistema jurídico pode decidir que foi crime doloso. Esta decisão que põe fim à discussão será a norma jurídica.

Esses significantes linguísticos, que podem consistir de textos, palavras orais e gestos, como em qualquer comunicação humana, são isso que os juristas há milênios têm denominado as fontes do direito. Esta visão realista e atual do processo de conhecimento do direito, compreensivelmente, foi precedida de uma longa evolução. 


\section{A ESTRATÉGIA DOGMÁTICA PARA EXCLUSÃO DO PROBLEMA ONTOLÓGICO: A DIFERENCIAÇÃO ENTRE FONTES MATERIAIS E FONTES FORMAIS}

No desenvolvimento histórico da teoria das fontes do direito, a dogmática jurídica do século XIX teve um papel importante, o qual foi apoiado por vigorosas correntes que buscavam dar apoio ao positivismo que se firmava. O tema sempre foi predominantemente filosófico e enfrentá-lo requeria incursões nessa área, sempre prenhe de controvérsias. Certamente é filosófica a pergunta sobre de onde ou de que vem o direito.

Diversas das fontes formais dogmáticas são as fontes "materiais", que designam as forças sociais das quais provêm as fontes formais. Isso porque toda fonte formal se origina de alguma realidade social, tais como ideologias, convicções morais e religiosas, dados biológicos, físicos, psicológicos, eventos históricos e assim por diante. Se o legislador coíbe o adultério para proteger a prole do marido, é devido ao dado biológico - pelo menos antes do exame de DNA - de que o homem não pode ter certeza sobre se aquele filho é seu. Se a lei de Estados muçulmanos se posiciona mais contra o consumo de álcool que de haxixe, e a lei de Estados cristãos vai em sentido inverso, é porque seu passado histórico lhes dá esse fundamento. Como toda fonte formal tem uma base material, autores há que recomendam a expressão fontes "formais-materiais" para as fontes formais. ${ }^{4}$ As fontes materiais perpassam a etiologia jurídica, isto é, o estudo das causas do direito, fatores que supostamente determinariam como as fontes formais surgiram, nesta ou naquela direção. Aí se dividem positivistas e naturalistas. Para os que defendem uma natureza do direito, metáfora que implica a ideia de normas acima das escolhas do direito positivo e seu governo efetivo, válidas em si mesmas, as fontes formais dependem de determinadas fontes materiais metafísicas. Mas a ideia de fontes materiais é retida também por alguns positivistas, mormente os de inclinação sociológica: para estes é preciso estudar de que fontes provém o direito, porém essas fontes são reais e empiricamente detectáveis.

Por isso a dogmática jurídica, o conjunto de conhecimentos sobre o direito que se consolidou com o positivismo da era moderna, instituiu estrategicamente a distinção entre fontes materiais e formais, com o objetivo de excluir as primeiras de seu campo de trabalho. Com a progressiva diferenciação entre os campos do saber e o surgimento das novas ciências sociais, essas fontes materiais ficariam a cargo da psicologia, da filosofia, da sociologia, da teologia e assim por diante, pois que ainda não tinham forma jurídica nem a coercitividade do direito positivo. Se é certo que toda fonte formal, como a lei e a jurisprudência, vem de uma fonte material que prevaleceu, investigar essas origens remotas não interessaria ao jurista.

4 Um exemplo desse sentido está em AFTALIÓN, Enrique e VILANOVA, José. Introducción al Derecho. 2a. ed. por Julio Raffo. Buenos Aires: Abeledo-Perrot, 1998, p. 632 s. 
Em sentido inverso, outros autores defendem que fontes materiais importantes são as religiosas, nas quais determinadas autoridades eclesiásticas interpretam os comandos da divindade e comunicam sua vontade às pessoas. As normas daí decorrentes, como a proibição do aborto ou a indissolubilidade do matrimônio, podem ser racionalmente compreendidas, mas o que vale mesmo é a revelação que vem da fé.

As filosofias que procuram fundamentar o direito em Deus e na religião enfrentam diversos problemas. O primeiro deles é quem será o intérprete dessa vontade metafísica, isto é, que não pode ser consultada por vias empíricas acessíveis a todos. Depois, os argumentos dos defensores das fontes materiais religiosas já conhecem de antemão as conclusões a que precisam chegar, pois a fé revela escolhas divinas válidas por si mesmas; o problema é que esses fundamentos não são uniformemente percebidos pelas autoridades religiosas, as quais se digladiam em torno das mais variadas questões éticas. Em terceiro lugar, embora aleguem que a razão precisa ser guiada pela fé, os defensores dessas fontes insistem que as mesmas são compatíveis com a razão e assim suficientes para convencer inclusive quem não tem fé, o que leva a uma redundância logicamente desnecessária. Finalmente, o que se percebe, quando se alegam fontes divinas, é que também elas surgem em contextos históricos que as podem explicar, como, por exemplo, o fato de os ordenamentos jurídicos muçulmanos terem menos tolerância do que os cristãos para com crimes como o furto; se fatos empíricos podem explicar o direito positivo, a revelação divina seria dispensável. ${ }^{5}$

Com tais objeções, dentre outras, os filósofos e juristas rejeitam as fontes materiais religiosas e advogam a necessidade de excluir esses argumentos da fundamentação do direito positivo.

Diante dessas dificuldades, outro grupo de autores abandona as referências religiosas e procura fundamentar as fontes formais do direito em postulados que lhes parecem exclusivamente racionais e assim demonstráveis para quaisquer seres humanos.

Mas as influências das fontes divinas continuam a aparecer na tentativa de uma concepção completa e abrangente sobre os fundamentos do direito, assim como no aspecto metafísico, que continua caracterizando as fontes materiais do direito. Os juristas e filósofos desta tendência, fortemente marcada pelo idealismo e depois pelo romantismo, apelam, ora menos, ora mais, aos dados empíricos, mas essas referências são sempre indemonstráveis.

Como exemplos dessas fontes materiais supostamente empíricas, podem-se citar o espírito absoluto ou objetivo de George Friedrich Hegel e Nicolai Hartmann; a vontade geral de Jean-Jacques Rousseau; o espírito do povo de Friedrich Carl von Savigny; o conjunto de dados da livre investigação

$5 \quad$ HAESAERT, Jean-Polydore. Théorie génerale du droit. Bruxelles: Bruylant, 1948. 


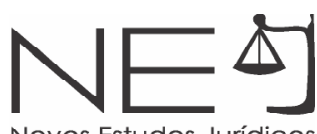

científica de François Gény; o querer vinculatório, autárquico e inviolável de Rudolf Stammler; a lista é longa. Não menos metafísicas, apesar de sua aparente vinculação aos dados empíricos, são a luta de classes da dialética de Karl Marx, ou os fatos normativos de Georges Gurvitch e da Escola do Direito Livre de Eugen Ehrlich e Hermann Kantorowicz.

Na procura por fundamentos empíricos para responder à pergunta sobre de onde vem o direito positivo, as tendências oriundas da psicologia remontam às essências fenomenológicas de Edmund Husserl e aos juristas seus discípulos, como Adolf Reinach, passando pela psicanálise de Sigmund Freud, seus continuadores e críticos. Procuram mostrar como a psique humana fornece uma base universal a partir da qual se pode conhecer o direito e separar as inclinações lícitas das ilícitas. O problema é a determinação concreta de conceitos vagos como "consciência jurídica" ou "justa natureza espiritual" do holandês Hugo Krabbe, mesmo que ele as considere objetivas e empiricamente perceptíveis. ${ }^{6}$

Há autores que defendem fontes materiais biológicas a partir das quais as fontes formais se constituem, ou seja, o direito e a ética não fazem parte de uma esfera específica, mas são determinados por características genéticas da espécie. Elas podem ser comuns a todos os seres humanos, como advoga Maurice Hauriou, ou servir de base para teorias eugênicas construídas sobre o conceito de raça de cada povo e contrárias a qualquer forma de miscigenação. No primeiro caso, o conceito de raça é rejeitado como vazio em termos de ciência biológica; no segundo, a finalidade do direito é a pureza racial. ${ }^{7}$

\section{FONTES FORMAIS PRIMÁRIAS E SECUNDÁRIAS E A QUESTÃO DA HIERARQUIA}

Uma vez excluída a questão das fontes das fontes, isto é, das fontes materiais do direito, aparecem dois novos problemas importantes, já no âmbito interno do positivismo jurídico: primeiro, definir quais são essas fontes; segundo, se sua aplicação for contraditória na solução de uma controvérsia jurídica, estabelecer sua hierarquia. Para isso, a teoria do direito dogmaticamente organizado da modernidade, a dogmática jurídica, separa as fontes formais em primárias e secundárias. Observe-se aqui, para evitar mal-entendidos, que diversos autores identificam o conceito de fontes primárias com o que aqui se chamou de fontes materiais. ${ }^{8}$ Somente para lembrar que é preciso atentar se, no contexto, trata-se de fontes primárias por oposição a fontes formais ou de fontes formais primárias em confronto com as fontes formais secundárias, como se vai fazer agora.

KRABBE, Hugo. Kritische Darstellung der Staatslehre. Den Haag: Nijhoff, 1930.

NICOLAI, Helmut. Rasse und Recht. Berlin: Hobbing, 1933.

ADEODATO, João Maurício. A retórica constitucional - Sobre tolerância, direitos humanos e outros fundamentos éticos do direito positivo. $2^{a}$. ed. São Paulo: Saraiva, 2009, p. 85 s. 
Tomando as expressões mais antigas, opta-se aqui pela dicotomia, mais tradicional, entre fontes primárias e secundárias. Mas esses mesmos adjetivos são complexos porque trazem dois sentidos contraditórios: por um lado, "primário" é o mais simples, menos sofisticado, menos complexo, ou seja, menos digno de atenção; por outro, "primário" é o principal, o que vem antes de secundário e lhe é superior, isto é, mais importante. A denominação escolhida não vai ser tão relevante, se se atenta para a significação dos termos.

Para exemplificar a dificuldade dessa classificação, observe-se a crítica feita por Carlos Cossio ao "primeiro" Hans Kelsen, sobre como classificar e hierarquizar o conceito de norma jurídica. Cabe ressaltar que ambos entendem a palavra "primária" no significado de mais importante do que "secundária". Para Cossio, a norma de conduta lícita, "dada a hipótese deve ser a prestação", seria a norma primária, ou "endonorma", porque a grande maioria das pessoas se conduz de acordo com ela ${ }^{9}$ e, por outro lado, a sanção não pode ser colocada como critério distintivo da norma jurídica, vez que toda norma tem sanção; ${ }^{10}$ para Kelsen, a norma de conduta ilícita, "dada a nãoprestação deve ser a sanção", seria norma primária, posto que só nela se mostra a coercitividade do direito, já que uma pessoa pode obedecer à norma de conduta ilícita por impulsos morais ou religiosos, não jurídicos. ${ }^{11}$ Observe-se que a diferença está antes na perspectiva dos autores do que em alguma característica "essencial" da norma jurídica e as posições são mais conciliáveis do que aparentam. Por isso propõe-se aqui um conceito diverso. Qual seja: a denominação de "primárias" para aquelas fontes formais básicas, as quais retiram sua coercitividade e sua validade de si mesmas e não precisam do acordo de outras, e de "secundárias" para aquelas que só valem se de acordo com as fontes primárias. Fontes formais primárias são então independentes de outras fontes formais, reclamam validade e obediência por pretender sua própria coercitividade. Fontes formais secundárias são também dogmáticas e coercitivas, mas só valem se coerentes com as fontes formais primárias. Assim é que, apesar de contratos em geral constituírem normas jurídicas, e assim serem obrigatórios, aquele que desobedeça aos requisitos da lei é inválido e sua obediência não deve ser reclamada. Por isso a lei é dita uma fonte formal primária e o contrato, uma secundária.

Ao enfrentar o primeiro problema, de classificação, os autores que se debruçaram sobre as fontes formais, em sua tradicional maioria, apesar de desacordos, apontam a lei, a jurisprudência e o costume como as fontes formais primárias, posição que se vai adotar aqui. Às vezes "corrige-se" a fonte "lei" por "legislação", sob o argumento de que a lei é o produto da legislação ou atividade legisladora, mas esse purismo não parece tão significativo.

COSSIO, Carlos. La teoria egológica del derecho y el concepto jurídico de libertad. 2a . ed. Buenos Aires: Abeledo Perrot, 1964, p. 305. DURKHEIM, Émile. Lições de sociologia. A moral, o direito e o Estado. Sem tradutor. São Paulo: T. A. Queiroz / EDUSP, 1983 , p. 3.

KELSEN, Hans. Allgemeine Theorie der Normen, Kurt Ringhofer und Robert Walter (Hrsg.). Wien: Manzsche Verlags- und Universitätsbuchhandlung, 1979, p. 18, 108 e 111-113 (Cap. 6, 32 e 34). 
Ressalve-se, por um lado, que essas três espécies de fontes devem ser entendidas em sentido muito amplo e, por outro, que elas trazem suas próprias hierarquias internas. Por exemplo, a constituição e a lei delegada são tipos de leis, mas não têm o mesmo peso em uma decisão sobre um conflito, enquanto o mesmo acontece com a súmula de um tribunal superior e o acórdão de um tribunal local, que fazem parte da jurisprudência. Além disso, a criatividade dos juristas traz novas classificações, as quais incluem nas fontes formais a autonomia da vontade de contratar e até vias para preenchimento de lacunas, como a analogia e os princípios gerais do direito, além da equidade.

Mas é no segundo problema, o da hierarquia entre as fontes formais primárias, que aparecem divergências mais profundas, as quais podem, para fins de clareza e simplicidade, ser colocadas em três grupos.

Para os legalistas, a corrente mais antiga do positivismo, a única fonte formal primária é a lei, a qual é inclusive identificada com "direito": somente o legislador cria o direito com caráter geral, obrigatório, ao passo que o juiz se limita a aplicá-lo aos casos concretos, numa rígida separação de poderes. Oriundos do iluminismo e da crença numa razão homogênea e esclarecida, os legalistas entendem que cada caso admite uma só decisão correta. Por isso qualquer interpretação deve ser evitada e, quando necessária, deve ser a mais literal possível, posto que "... a própria natureza da constituição requer que os juízes sigam a letra da lei" e "para isso ele precisa simplesmente abrir os olhos."12

Apesar de ainda hoje presente em diversas constituições e alardeada por boa parte da doutrina, inclusive a brasileira, o legalismo e sua separação de poderes eram combatidos por seus contemporâneos, como a Escola Histórica e a Escola da Jurisprudência dos Conceitos. Para os juristas aqui denominados normativistas, que vão culminar em Kelsen, já no século XX, o juiz cria, sim, o direito, e não há muito sentido em dizer que a lei é fonte formal primária hierarquicamente superior à jurisprudência. Se a sentença pode ser considerada uma fonte formal secundária, pois pode ser invalidada quando reconhecida ilegal, por exemplo, o mesmo não se pode dizer de uma jurisprudência definitiva, vez que é ela que vai determinar o significado da lei. Dizer que uma decisão jurisprudencial definitiva é contra a lei pressupõe algum critério superior para tal juízo, o qual simplesmente não existe. Daí o normativismo alegar que a lei e a jurisprudência são ambas fontes formais primárias, posto que inseparáveis, faces da mesma moeda: a lei significa aquilo que a jurisprudência diz que ela significa.

Para o argumento de que o costume é também uma fonte formal primária, é crucial a aceitação do costume contra legem como direito. Sim, porque o normativismo aceita tranquilamente o costume como fonte formal secundária, ou seja, válido e aplicável se de acordo com a lei. O problema de verificar se o costume jurídico tem força própria aparece quando ele se efetiva por sua própria força

12 MONTESQUIEU, Charles Louis de Secondat, Baron de la Brede et. De l'Esprit des Lois. Nouvelle édition. Paris: Garnier, sem data, Livro VI, 3. 
coercitiva e aplica-se inclusive em detrimento dos comandos do Estado. Ao defender tal postulado, essa terceira forma de positivismo, chamada de sociologista ou simplesmente realista, contraria Kelsen em seu exemplo de que as normas efetivas entre um "bando de salteadores" não podem ser entendidas como direito. ${ }^{13}$ Para ela, a validade procedimental da criação estatal do direito é deixada de lado e o critério passa a ser a efetividade ou eficácia social: se a comunidade segue comandos contrários aos do Estado, estes é que não podem ser chamados de direito por carecerem de "realidade" diante das condutas. O mesmo se aplica em relação aos contratos que desobedecem à lei: se efetivamente são cumpridos, são jurídicos, pois o direito eficaz prevalece sobre o direito válido.

\title{
3. FONTES NÃO ESTATAIS DO DIREITO E A PRETENSÃO DE EXCLUSIVIDADE: O COSTUME JURÍDICO
}

Conectado ao problema das fontes formais primárias e secundárias está o das fontes estatais. Para os positivistas, que entendem que as fontes estatais são as únicas primárias, o direito positivo é obviamente reduzido ao direito produzido ou chancelado pelo Estado.

Nas primeiras manifestações que deram nascimento longínquo ao direito moderno, a fonte primordial do direito é o povo e, como em todas as civilizações primitivas, o direito é primordialmente costumeiro. Os especialistas divergem sobre o que significava o costume para os antigos romanos, em cujos escritos aparecem três expressões nesse sentido: usus, mos e consuetudo. A primeira palavra relaciona-se com uma evolução da palavra grega ethos, que resulta da porosidade de duas palavras parecidas, mas com

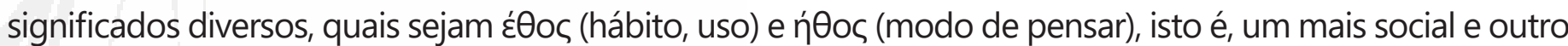
mais pessoal, com a diferença apenas na primeira letra da palavra. O significado original, de mais interesse agora, pode ser, nos primórdios, traduzido por habitat, aplicado inclusive ao ambiente dos animais. Só depois a metáfora se desenvolve para exprimir caráter e maneira de ser de um povo ou indivíduo.

\begin{abstract}
Há um único passo nas fontes jurídicas romanas, em que a palavra usus tem o sentido de verdadeira fonte de direito: Trata-se duma constituição do imperador Constantino, do ano 319. Independentemente das diversas explicações dadas por vários romanistas, devemos ter presente que esse texto pertence à época pós-clássica; ora a característica geral desta época, como sabemos é a confusão; não admira, pois, que um texto pós-clássico confunda usus com mores maiorum e sobretudo com consuetudo. ${ }^{14}$
\end{abstract}

Desde essa época o costume está ligado à ideia de efetividade, obediência uniforme e constante a determinada regra, larga et inveterata consuetudo, somada à convicção psicológica, subjetiva, de que todos estavam a ele obrigados. A expressão mores maiorum surge quando o usus já adquiriu uma "forma" juridicamente aplicável, uma medida, como nomos na Grécia. Daí os romanos começarem

\footnotetext{
13 KELSEN, Hans. Reine Rechtslehre. Wien: Verlag Österreich, 2000 (2. Vollständig neu bearbeitete und erweiterte Aufl. 1960), p. 49. Ver a tradução portuguesa de João Baptista Machado: Teoria pura do direito. Coimbra: Arménio Amado Ed., 1976, p. 81. 


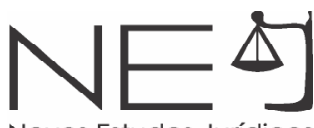

a falar de instituta maiorum, o que tornava uma contradictio in terminis, falar de "maus costumes", pois o costume era naturalmente bom, moral e jurídico, tal qual fenômenos da natureza, irresistíveis porque devem necessariamente ocorrer.

O processo de formação do costume, como sói acontecer, tem base antropológica. A tendência à imitação no comportamento dos animais vertebrados "superiores" já havia sido percebida por Charles Darwin no começo do século XIX. ${ }^{15} \mathrm{Na}$ linguagem comum, diz-se que os símios gostam de "macaquear", porém as pessoas agem da mesma maneira. As pesquisas mais recentes sobre o cérebro humano discorrem sobre os chamados "neurônios-espelho", responsáveis pela imitação e por comportamentos como a empatia, os quais são muito importantes na capacidade de adaptação dos humanos a diferentes ambientes e situações. ${ }^{16}$

Um hábito pode ser individual, aquele que cada pessoa adquire ao longo da vida, dentro de uma invariabilidade infinita, e também coletivo, aquele que se torna dominante nas condutas de muitas pessoas, tais como escovar os dentes ou viver com animais domésticos. Esses hábitos coletivos são denominados usos sociais.

Um ponto de observação importante, nessa passagem do uso para o costume, pode ser um olhar sobre a moda como instituição social. ${ }^{17}$

A moda é um dos sinais da modernidade: ela se baseia na "permanência da mudança", ou na "conformidade do desvio", paradoxos para as concepções tradicionais de racionalidade: todos querem ser originais, dessemelhantes, e nesse objetivo se assemelham. A função da moda está em funcionalizar esses paradoxos, na medida em que os banaliza e assim os neutraliza, é um caminho para entender o costume como forma de organização. Em outras palavras, há racionalidade na moda, ao produzir e usar a irracionalidade.

Esse fenômeno radica na antropologia, pois a humanidade não é social no sentido de gregária ou solidária, são animais políticos que têm em comum seu egoísmo, indivíduos que dependem dos demais até para pensar e entender o mundo, mas que sempre objetivam autonomia. Por isso o ser humano tem uma atração por tudo que é novo e diferente, confrontando o papel estabilizador do costume como fonte material.

A moda no sentido estrito, moderno, nem sempre existiu, nem sequer a denominação. Tinha significado mais amplo e profundo que o de hoje, praticamente resumido a roupas e acessórios, quando não aplicado pejorativamente a outros setores, como a intelectuais, cientistas, jornalistas ou

\footnotetext{
15 DARWIN, Charles. The origin of species. 6th edition. London: Global Grey E-books, 2018 (1872), p. 403.

16 GEHLEN, Arnold. Der Mensch - seine Natur und seine Stellung in der Welt. Wiebelsheim: Aula-Verlag, 2009 , p. 130 s.

17 MÜLLER, Eveline. Georg Simmels Modetheorie. Zürich: Soziologisches Institut der Universität Zürich, Oktober 2003.
} 
professores. Uma notória característica da era moderna é olhar para o novo e o futuro, pois sociedades pré-modernas sempre se baseiam na estabilidade da tradição. A moda é um dos sinais mais evidentes dessa modificação, assim como o direito positivo, que institucionaliza a mutabilidade por meio do procedimento. ${ }^{18} \mathrm{~A}$ adaptação ao novo é a única forma de estabilidade para uma sociedade que não se baseia no passado, mas no futuro. Porém, como a criatividade é limitada, diante da contingência ilimitada do mundo, a moda tende a voltar sempre, imitando a si mesma no passado.

Na sociedade complexa, há o paradoxo da conformidade com o desvio: a sociedade ocidental tradicional sabia o que esperar de cada indivíduo, dentro de uma estrutura hierarquizada, na qual não se precisava lidar com os mistérios da personalidade de cada um. Na modernidade, a sociedade é constituída por indivíduos "singulares e idiossincráticos", cada qual procurando sua originalidade, objetivando ser reconhecido como sujeito único, autêntico, imprevisível. É curioso observar que as referências a serem imitadas eram heróis, santos, o bom, o belo, o justo, o admirável em algum sentido. As referências atuais da moda, ao contrário, imitam grupos minoritários e periféricos na sociedade, tais como prisioneiros, ciganos, moradores de rua, uma vez que grupos desfavorecidos implicam recusar a conformidade, desviar-se, ser original. Espelha indivíduos que ninguém quer ser. Da moda ninguém escapa, pois ser intencionalmente fora de moda implica o mesmo fenômeno, do lado da recusa. ${ }^{19}$ Contudo, a moda pode ser classificada como um uso social, não um costume jurídico. Alguns "usos" são definidos como "costumes", mas há grande desacordo sobre quando determinado uso social se torna costume jurídico, exatamente porque os juristas divergem quanto aos critérios para essa distinção. Pode-se dizer que a obrigatoriedade é tida como critério básico desde os antigos romanos, conforme colocado acima. Como o costume surge espontaneamente, essa obrigatoriedade faz inicialmente parte de uma convicção psicológica generalizada naquele grupo social. Por isso os juristas apontam esse elemento subjetivo, além do elemento objetivo da coercitividade. O direito consuetudinário surge, portanto, não por um processo estatal formal, mas de um exercício mais longo, que deve ser permanente e constante, uniforme e geral (longa et inveterata consuetudo), e reconhecido como legalmente vinculativo pelo grupo social envolvido (opinio iuris necessitatis).

Com a constituição do Estado moderno e da filosofia que o acompanha, o juspositivismo em sentido amplo, constrói-se também a pretensão de monopólio do direito, a ideia de que todo direito é positivo e, se não emana diretamente dos órgãos burocratizados do Estado, precisa se subordinar aos critérios por eles fixados. No caso de uma fonte formal do direito espontaneamente criada pelos grupos sociais, como o costume, essa compatibilidade pode vir a ser um problema. ${ }^{20}$

18 LUHMANN, Niklas. Legitimation durch Verfahren. Frankfurt a.M.: Suhrkamp, 1983.

19 ESPOSITO, Elena. Originality through imitation: the rationality of fashion. Zentrum für interdisziplinäre Forschung - Mitteilungen. Bielefeld: Universität Bielefeld, 2017, p. 23-32.

20 BRONZE, Fernando José. Lições de introdução ao direito. Coimbra: Coimbra Editora, 2002, p. 127, chama essa pretensão de monopólio de "estadualidade" do direito: $6^{a}$ Lição, 2) b $\beta$ "A insuficiência ainda da complementar qualificação pela estadualidade - algumas notas sobre a relação entre a estadualidade e a juridicidade." 
Para o positivismo, legalista ou normativista, o costume deve ser reconhecido pela lei ou aplicado pelos tribunais para se tornar efetivamente uma fonte formal do direito, daí sua classificação em secundum legem, praeter legem e contra legem, sem que este último seja aceito como direito: o costume jurídico é, portanto, uma fonte formal secundária, dependente da lei e da jurisprudência. Para o positivismo sociologista ou realista, por seu turno, o costume é uma fonte formal primária e, em caso de confronto com regras estatais, o chamado costume contra a lei, o critério decisivo será a efetividade ou eficácia social, ou seja, qual das soluções prevalece no caso concreto, se a legal ou a ilegal.

O costume secundum legem é aquele a que a lei se reporta expressamente, reconhecendo sua obrigatoriedade, e assim não oferece problemas de conciliação com o direito estatal. A lei Ihe faz referência com função de complementá-la, de forma semelhante ao costume praeter legem, com a diferença de que remete a instância responsável pela decisão diretamente ao costume, sem que o texto deixe espaço para que se resolva se há lacuna no caso concreto. Dois exemplos:

Código Civil, Art. 615. Concluída a obra de acordo com o ajuste, ou o costume do lugar, o dono é obrigado a recebê-la. Consolidação das Leis do Trabalho, art. 458. Além do pagamento em dinheiro, compreende-se no salário, para todos os efeitos legais, a alimentação, habitação, vestuário ou outras prestações in natura que a empresa, por força do contrato ou do costume, fornecer habitualmente ao empregado.

A Lei de Introdução às Normas do Direito Brasileiro diz em seu art. 40: "Quando a lei for omissa, o juiz decidirá o caso de acordo com a analogia, os costumes e os princípios gerais de direito." ${ }^{21}$ Ela mostra a inspiração legalista do legislador, apesar de datar do ano de 1942 e ter sido ratificada em 2000 e 2018. Ora, se há costume, a rigor não há lacuna, somente lacuna na lei, pois o costume é uma fonte formal do direito. Mesmo para o juspositivismo normativista. Na mesma direção vai a Consolidação das Leis do Trabalho:

Art. $8^{\circ}$. As autoridades administrativas e a Justiça do Trabalho, na falta de disposições legais ou contratuais, decidirão, conforme o caso, pela jurisprudência, por analogia, por equidade e outros princípios e normas gerais de direito, principalmente do direito do trabalho, e, ainda, de acordo com os usos e costumes, o direito comparado, mas sempre de maneira que nenhum interesse de classe ou particular prevaleça sobre o interesse público. ${ }^{22}$

O costume praeter legem é aquele em que pensou o legislador brasileiro ao redigir o art. $4^{\circ}$ da Lei de Introdução, que em nada mudou a respeito, desde 1942. É um costume que complementa, mas não contraria a lei, oferecendo uma das vias para preenchimento de lacunas no sistema estatal. Por isso sempre foi aceito pelo positivismo estatal, de viés kelseniano, ainda que, como dito, como fonte formal secundária.

O costume contra legem é também chamado de costume ab-rogatório, mas essa segunda denominação já pressupõe por resolvido o problema central do fenômeno, isto é, se o costume 
pode ab-rogar a lei, ou seja, simplesmente revogá-la, além de confundir os efeitos do costume contra legem com os do desuso. Na base da discussão está o mesmo problema, de se o direito deve ser reconhecido a partir de sua validade estatal ou de sua eficácia social. A jurisprudência, inclusive, em países periféricos, caracterizados pela ineficiência estatal, como o Brasil, tem reconhecido efeitos lícitos a costumes manifestamente ilegais, como direitos trabalhistas decorrentes do jogo do bicho, da prostituição, do trabalho do menor. A base dogmática para esse tipo de decisão é com frequência o artigo $5^{\circ}$ da mesma Lei de Introdução: "Na aplicação da lei, o juiz atenderá aos fins sociais a que ela se dirige e às exigências do bem comum", texto altamente impreciso.

Há que referir também a figura do desuso, ou desuetudo, conceito distinto do de costume contra legem. A semelhança responsável pela imprecisão é que, em ambos os casos, o comando do Estado é ignorado. Porém, enquanto que, no costume contra legem, há uma norma costumeira contrária ao direito estatal, no desuso este direito é tão somente ignorado, sem que se coloque uma conduta diversa em contrário, pois o fato disciplinado pela lei, "letra morta", passa a ser juridicamente irrelevante.

Em geral, com a hipercomplexidade social crescente, a perda de relevância do costume, no Brasil, vem desde a "Lei da Boa Razão", de 1769, na era pombalina, a qual recusou expressamente seu acolhimento, se contrário à lei. Dita lei dirigia-se precisamente às fontes e é um marco na pretensão estatal de monopólio na criação do direito na cultura lusitana, tendo inclusive desautorizado os complementos ao Corpus Juris Civilis introduzidos pela doutrina de glosadores do final do Medievo, como Bartolo de Sassoferrato e Francesco Accursio.

Para um exemplo da importância do costume na história do direito brasileiro, nada obstante, é interessante o caso do concubinato. Aluísio de Azevedo, em seu livro O cortiço, já em 1890, mostra sem rodeios a injustiça social do interesse econômico e o desvalor da companheira, que em tudo ajuda e é depois desprezada à míngua. Sem qualquer pudor, João Romão descarta Bertoleza e a faz voltar à condição de escrava, provocando seu suicídio, para casar com a rica e branca Zulmira, filha de seu antigo desafeto. ${ }^{23}$

Diante dos preconceitos, denunciados pela literatura e logo encampados pela doutrina, restou à justiça brasileira conceder os direitos à concubina sob o argumento dogmático de desconsiderar a afetividade (more uxorio) e apelar por analogia à figura da sociedade de fato, em 1963, por meio da Súmula 380, afirmando que "... a sociedade de fato, e não a convivência more uxorio, é o que legitima a partilha dos bens entre os concubinos". ${ }^{24}$ De uma simples negativa de quaisquer direitos à concubina, vez que constituiria enriquecimento ilícito fruto de uma "relação imoral", sem consideração pelos "laços sagrados do matrimônio", evolui-se para o reconhecimento do direito à indenização ou mesmo 
à meação, segundo houvesse ou não patrimônio a ser partilhado. Sendo o componente econômico da sociedade conjugal o fator determinante, e não o sexo ou a afetividade do concubinato, isso também ajudou no sentido do reconhecimento da meação patrimonial entre pessoas do mesmo sexo, início do processo de legitimação jurídica da união familiar entre homoafetivos.

\section{AS RAZÕES DA DOUTRINA COMO FONTE DO DIREITO}

Nos dias de hoje pode causar surpresa os livros e os professores de introdução ao direito colocarem a doutrina como fonte do direito, ao lado da lei, da jurisprudência, do costume e da autonomia da vontade. Diga-se que o principal motivo para a doutrina ser até hoje discutida como fonte do direito tem suas raízes em Roma. O Corpus Juris Civilis de Justiniano I, que subiu ao trono em Constantinopla em 527 d.C., foi compilado a partir do ano de 529, sofreu diversas alterações, teve sua versão final promulgada em 534 e foi a mais importante fonte do direito na Europa até a modernidade.

Essa compilação não se compunha apenas de leis, mas também de orientações jurisprudenciais e doutrina. Sabe-se que o chamado "tribunal dos mortos" consistia no conjunto de opiniões dos cinco grandes juristas, Gaio, Papiniano, Modestino, Paulo e Ulpiano, e pesava mais nas decisões da Roma clássica do que qualquer outra fonte do direito, mais do que a lei ou o direito pretoriano. Ou seja: o Corpus era muito importante dentre as fontes e, em seu seio, a doutrina era fundamental.

O Codex era uma consolidação de todas as leis romanas anteriores recepcionadas em Constantinopla. O Digesto ou Pandectae resultou da compilação da doutrina propriamente dita e excluía expressamente como inválida qualquer orientação que não constasse de seus 50 livros. As Institutas, inspiradas na obra de mesmo nome, de Gaio, compunham-se de textos mais elementares e esquemas pedagógicos destinados à educação dos jovens juristas. As Novellae foram publicadas por último e, como o nome diz literalmente, continham as novas leis do próprio Justiniano, aquelas decretadas após a revisão do Codex e a ele acrescentadas.

Vários séculos se passaram sem que aparecessem juristas no nível técnico dos romanos, além do respeito para com um povo antigo e sábio, na visão das nações posteriores, oriundo de uma cidade que era a sede da Cristandade. O simples passar do tempo trouxe ainda mais autoridade ao seu maior monumento jurídico, o Corpus, e o fato de ser escrito foi-lhe dando força de "lei" - o texto da norma que se comunica por meio da leitura e cuja aplicação se pretende geral, muito diferente dos costumes medievais localizados -, ainda que, como dito, seu conteúdo abrangesse todos os tipos de fontes formais do direito: legislação, jurisprudência, costumes e doutrina. 
Por fazer parte do conteúdo do Corpus Juris Civilis, a doutrina foi assim considerada fonte formal do direito, confundida com a própria lei; a princípio, a doutrina romana original, depois, a doutrina mesma dos juristas contemporâneos, sobretudo a partir da Escola de Bolonha e dos glosadores do próprio Corpus, os quais o explicavam e até complementavam, adaptando-o ao direito do tempo e lugar. Na época de hoje, certamente a doutrina não é uma fonte formal, dogmática, do direito positivo. Em primeiro lugar por sua falta de uniformidade, vez que os doutrinadores divergem sobre todos os temas e, por isso mesmo, podem-se encontrar doutrinas para todos os gostos. Mais ainda, a doutrina se compra, o que the retira a condição de fonte: não se pense que um parecerista é contratado para fornecer sua perspectiva "doutrinária", mas sim para dar uma opinião que apoie os interesses localizados do contratante.

Ainda assim, a doutrina, como amálgama dos debates dos doutos em direito, pode ser dita como uma das vanguardas importantes para as fontes formais e também como a fonte material mais importante do direito, dentre aquelas que constituem a opinião pública. Uma autoridade reconhecida na área jurídica, desinteressada e cientificamente focada, pode ser sobremaneira importante na evolução do que se entende por direito, pois, se a ideologia de quaisquer grupos sociais é fonte material do direito, mais ainda o será a opinião daqueles que fazem do direito seu campo de pesquisa. O caráter mercantilista da indústria de pareceres no Brasil tem enfraquecido a força da doutrina, é certo, mas este deve ser, esperançosamente, um fenômeno passageiro. Veja-se um exemplo mais detalhado de evolução da tolerância, sobre o problema jurídico do adultério, na posição de um doutrinador brasileiro na área de direito de família. ${ }^{25}$

Começa com uma sugestão mais igualitária, crítica à interpretação dominante anterior, segundo a qual o adultério do esposo só se daria se houvesse "concubina teúda e manteúda". A proposição do autor é que também a aventura ocasional caracterizaria adultério.

Mas logo acrescenta, como pessoa de seu tempo:

Entretanto, do ponto de vista puramente psicológico, torna-se sem dúvida mais grave o adultério da mulher. Quase sempre, a infidelidade no homem é fruto de capricho passageiro ou de um desejo momentâneo. Seu deslize não afeta de modo algum seu amor pela mulher. O adultério desta, ao invés, vem demonstrar que se acham definitivamente rotos os laços afetivos que a prendiam ao marido e irremediavelmente comprometida a estabilidade do lar. Para o homem, escreve Somerset Maugham, uma ligação passageira não tem significação sentimental ao passo que para a mulher tem.

25 MONTEIRO, Washington de Barros. Direito de família. Curso de direito civil, $2^{\circ}$ Vol. $9^{a}$ ed. revista e ampliada. São Paulo: Saraiva, 1970, p. 112 Essa discussão foi retirada das edições posteriores, após o falecimento do autor. 
Depois vem um argumento pragmático, que hoje estaria muito enfraquecido:

Além disso, os filhos adulterinos que a mulher venha a ter ficarão necessariamente a cargo do marido, o que agrava a imoralidade, enquanto os do marido com a amante jamais estarão sob os cuidados da esposa. Por outras palavras, o adultério da mulher transfere para o marido o encargo de alimentar prole alheia, ao passo que não terá essa consequência o adultério do marido. Por isso, a própria sociedade encara de modo mais severo o adultério da primeira.

Justiça seja feita, ele diz logo depois:

Observe-se, porém, que do ponto de vista moral e jurídico, entre as duas infrações inexiste qualquer diferenciação: ambas atentam contra lei, a moral e a religião, dissolvem o casamento e provocam a dissolução da família. Merecem, pois, idêntica reprovação.

Com sua força vanguardista, a doutrina também revela ao historiador a evolução do direito positivo, ajuda, no problema do conhecimento, a superar os abismos entre significantes e significados: apresenta-se outro exemplo, quando é preciso definir se determinada pessoa que sofreu violência sexual no caso concreto é ou não uma mulher, o que pode ser problemático, diante dos progressos da medicina, quando se questiona por que uma pessoa do sexo masculino, sexualmente violentada, deve ser encarada como vítima do crime de estupro, atentado violento ao pudor ou lesão corporal.

\section{AUTONOMIA DA VONTADE E DO CONTRATO COMO FONTE NEGOCIAL}

Não há dúvida de que seja fonte formal, dogmática e dotada de coercitividade. A discussão, semelhante ao que ocorre com o costume, posto tratar-se também de fonte não estatal, é definila como fonte primária ou secundária. Sua característica mais marcante é que se trata de fonte de obrigações específicas, que não se dirigem a um universo qualquer de pessoas, mas exclusivamente às partes que manifestam a ela seu aceite.

O problema é, consequentemente, saber se contratos contra legem podem ser considerados jurídicos, ou seja, se a livre manifestação de vontade basta ou se o acordo com a lei é essencial. A contradição está em que o direito estatal, pelo menos no ambiente periférico como o brasileiro, tem aceitado efeitos de contratos contrários à lei, como no caso de direitos trabalhistas oriundos de trabalho escravo. Para muitos autores, a vontade das partes seria o núcleo da relação contratual, exercendo a lei apenas papel supletivo. Para outros, contudo, os limites da lei são preponderantes, cabendo a coercitividade do contrato somente se de acordo com as normas estatais.

Questão correlata aparece quando se discutem os tratados, os pactos e as convenções do direito internacional como fonte do direito. Da mesma maneira, certamente são fontes formais, o 
problema é se primárias ou secundárias. Para Max Weber, o direito só merece tal nome se coercitivo, o que excluiria o direito internacional:

Desde logo, segundo a terminologia aqui escolhida (como conveniente), não se pode na realidade designar como direito uma ordem [o d. internacional] que só está garantida pelas expectativas da reprovação e das represálias daqueles que são lesados, quer dizer, convencionalmente e pela situação de interesses, e que careça de um quadro de pessoas especialmente destinado a impor seu cumprimento ${ }^{26}$.

A fonte convencional da autonomia da vontade, então, deve ser entendida, pelo menos no momento presente, como fonte formal secundária, nos termos da filosofia positivista dominante.

\section{CONSIDERAÇÕES FINAIS}

A teoria das fontes do direito, como se vê, está presente em toda a civilização ocidental, ainda que seu conteúdo varie ao longo de cada época, adapta-se a certa "moda" social, indo da teologia à metafísica e desta à ciência. Tais teorias, dessa forma, utilizam-se das mesmas premissas, embora cheguem a conclusões totalmente opostas. O omnis potestas a Deo do jusnaturalismo teológico, por exemplo, justificou a tirania, a solidariedade dos direitos do homem, a supremacia do Estado. Assim, os significados das expressões fontes materiais e formais primárias ou secundárias parecem constituir uma reação pró ou contra a ordem positiva vigente.

Para que apareça essa controvérsia, é importante uma ordem social na qual o indivíduo se manifeste em relação à própria consciência, assumindo ser distinto da sociedade. Em outras palavras, é preciso existir a noção de sujeito e direito subjetivo. Ambas as ideias são conexas e de grande importância na civilização ocidental: a origem do direito e a noção de indivíduo. ${ }^{27}$ Essa visão histórica e pragmática concentra-se sobre a ideia de que as fontes primárias e naturais do direito representam alguma reação do indivíduo diante dos constrangimentos sociais a que está submetido. Sem chegar a afirmar que o conceito de sujeito é mero produto de infraestruturas econômicas, pode-se sugerir que ele constitui um recurso daqueles que se sentem de qualquer forma oprimidos pelo direito positivo, contra essa ordem que resiste a suas individualidades.

\section{REFERÊNCIAS DAS FONTES CITADAS}

ADEODATO, João Maurício. A retórica constitucional - Sobre tolerância, direitos humanos e outros fundamentos éticos do direito positivo. $2^{\text {a }}$. ed. São Paulo: Saraiva, 2009.

AFTALIÓN, Enrique e VILANOVA, José. Introducción al Derecho. 2ª. ed. por Julio Raffo. Buenos Aires: Abeledo-Perrot, 1998.

26 WEBER, Max. Wirtschaft und Gesellschaft - Grundriss der verstehenden Soziologie, Johannes Winckelmann (Hrsg.). Tübingen: Mohr-Siebeck, 1985, Kap. I, § 6, 2, p. 18.

27 LADEUR, Karl-Heinz. Der Anfang des westlichen Rechts - Die Christanisierug der römischen Rechtskultur und die Entstehung des universalen Rechts. Tübingen: Mohr Siebeck, 2018, p. 134. 
AZEVEDO, Aluísio. O cortiço. 30. ed. São Paulo: Ática, 1997.

BRASIL. Decreto-Lei n 4.657, de 4 de setembro de 1942 (Lei de Introdução ao Código Civil Brasileiro).

BRASIL. Decreto-Lei n 5.452, de $1^{\circ}$ de maio de 1943 (Consolidação das Leis do Trabalho).

BRASIL. Lei 13.655, de 25 de abril de 2018 (Lei de Introdução às Normas do Direito Brasileiro).

BRONZE, Fernando José. Lições de introdução ao direito. Coimbra: Coimbra Editora, 2002.

COSSIO, Carlos. La teoria egológica del derecho y el concepto jurídico de libertad. $2^{\mathrm{a}}$. ed. Buenos Aires: Abeledo Perrot, 1964.

CRUZ, Sebastião. Direito romano - lições. $4^{a}$ ed. Coimbra: Coimbra Editora, 1984, p. 163.

DARWIN, Charles. The origin of species. 6th edition. London: Global Grey E-books, 2018 (1872).

DURKHEIM, Émile. Lições de sociologia. A moral, o direito e o Estado. Sem tradutor. São Paulo: T. A. Queiroz / EDUSP, 1983.

ESPOSITO, Elena. Originality through imitation: the rationality of fashion. Zentrum für interdisziplinäre Forschung Mitteilungen. Bielefeld: Universität Bielefeld, 2017.

GEHLEN, Arnold. Der Mensch - seine Natur und seine Stellung in der Welt. Wiebelsheim: Aula-Verlag, 2009.

HAESAERT, Jean-Polydore. Théorie génerale du droit. Bruxelles: Bruylant, 1948.

KRABBE, Hugo. Kritische Darstellung der Staatslehre. Den Haag: Nijhoff, 1930.

LADEUR, Karl-Heinz. Der Anfang des westlichen Rechts - Die Christanisierug der römischen Rechtskultur und die Entstehung des universalen Rechts. Tübingen: Mohr Siebeck, 2018.

LUHMANN, Niklas. Legitimation durch Verfahren. Frankfurt a.M.: Suhrkamp, 1983.

MONTEIRO, Washington de Barros. Direito de família. Curso de direito civil, $2^{\circ}$ Vol. $9^{a}$ ed. revista e ampliada, São Paulo: Saraiva, 1970.

MONTESQUIEU, Charles Louis de Secondat, Baron de la Brede et. De l'Esprit des Lois. Nouvelle édition. Paris: Garnier, sem data.

MÜLLER, Eveline. Georg Simmels Modetheorie. Zürich: Soziologisches Institut der Universität Zürich, Oktober 2003.

NICOLAl, Helmut. Rasse und Recht. Berlin: Hobbing, 1933.

REALE, Miguel. Fontes e modelos no direito - para um novo paradigma hermenêutico. São Paulo: Saraiva, 1994.

SUPREMO TRIBUNAL FEDERAL. Súmula 380 de 1963. Revista Trimestral de Jurisprudência, vol. 79. Brasília: 1977.

WEBER, Max. Wirtschaft und Gesellschaft - Grundriss der verstehenden Soziologie, Johannes Winckelmann (Hrsg.). Tübingen: Mohr-Siebeck, 1985.

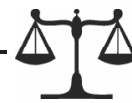

RECEBIDO EM: 15/08/2019

APROVADO EM: 25/10/2019 